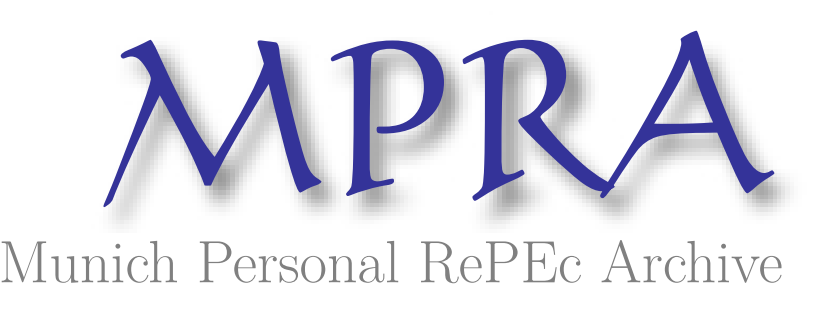

\title{
A Radical Shift in Managing Risks: Practical Applications of Complexity Theory
}

Chichilnisky, Graciela

January 1998

Online at https://mpra.ub.uni-muenchen.de/7881/

MPRA Paper No. 7881, posted 22 Mar 2008 07:21 UTC 


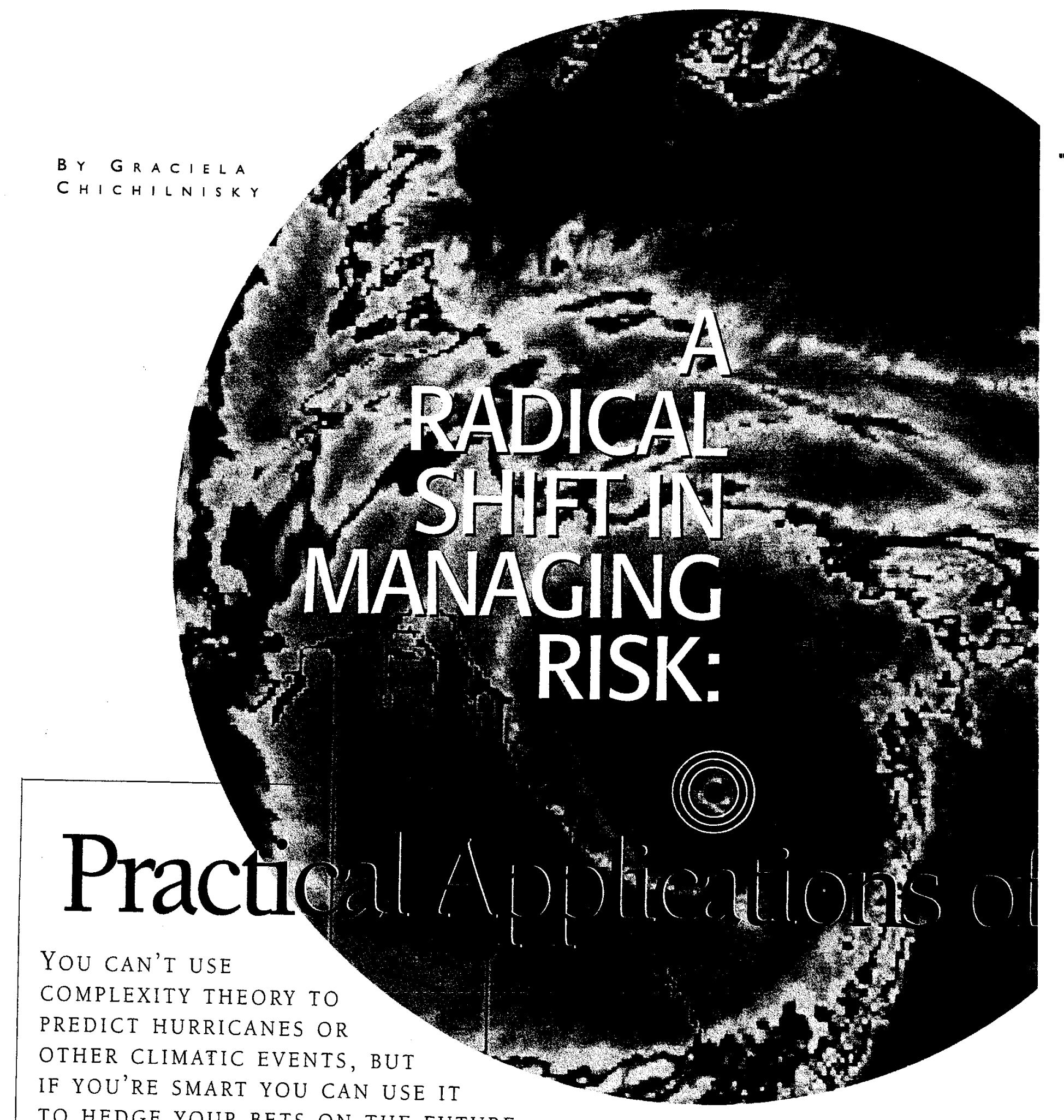

TO HEDGE YOUR BETS ON THE FUTURE.

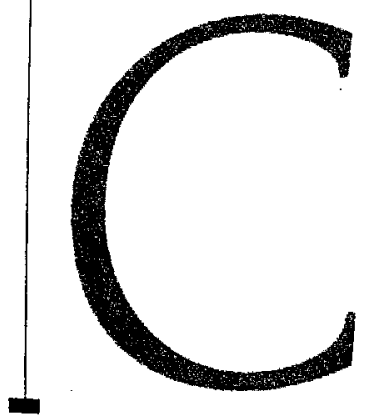

omplexity theory is designed to bring order out of a rough-andtumble world, something close to every insurance professional's or actuary's heart. Whether applied in the laboratory or as part of a mathematical model, it can do wonderful things. But in the real world it's just what its name says-a theory. It may help us understand why things go one way or another, but it can't foretell those things with such certainty that an insurance company could, say, set its rates based on the knowledge that only one hurricane will strike Florida during the coming year.

GRACIELA CHICHILNISKY IS UNESCO PROFESSOR OF MATHEMATICS AND ECONOMICS aNo diRector, PRogram on INFORMATION AND RESOURCES, COLUMBIA UNIVERSITY, NEW YORK CITY.

WEATHER MAP COURTESY OF THE NATIONAL OCEANIC AND ATMOSPHERIC ADMINISTRATION 
Yet I see a connection between complexity theory and risk management, which is the essence of insurance. In particular, I've focused on the risk management of complex systems.

Admittedly, the prediction of complex systems is inherently difficult, even impossible, according to some prominent writers (see sidebar on p. 30). But I want to take a position closer to analysts who say that, if you're smart enough, you can sometimes discern patterns, even in chaos. There are situations when you can actually make predictions, providing you have the right instruments. So what's needed for better risk management is something in the nature of a gestalt shift and, in particular, financial innovation.

In short, what's needed is a new method of predicting. And here the function is not to know the future (though people may tell you it is). In finance, analysts are not trying to predict the future (nobody can really do that); instead, they hedge against the risk of a downside future event. Whether we can predict the future is beside the point-it's a misunderstanding of the true nature of the problem. The real challenge is knowing how to hedge effectively against an adverse event. After all, if the future were predictable, there'd be no need for insurance in the first place. All that would be required is a steady accumulation of funds sufficient to pay the resulting losses when a predicted event occurred.

Given that we can't predict events, we must rely on financial innovation. In particular, we must focus on complex systems. They're the most difficult, but they're frequently the best representation of how the world works today. With a bit more sophistication and financial innovation, we can deal with these systems fairly easily. The scheme suggested here won't do a perfect job-nothing can-but it provides a new way of managing and accounting for risk, and of dealing with apparent chaos.

\section{Order from Chaos}

The key observation behind all my work comes from mathematics and chaotic systems: Most chaotic systems exhibit order, and that order is given by what are called "chaotic attractors." This means even systems that are difficult to make predictions about, and difficult to observe, will eventually settle into patterns.

Think, for instance, about the weather. Perhaps you've been told that, as a result of the chaotic attractors, there are two possible patterns into which the weather may settle. In one, there will be a high probability of 10 intense and destructive tornadoes. Conversely, in the other pattern, there are clear skies and an absence of intense storms.

\section{Complexity Theory}

In essence, there are two corresponding actuarial tables for catastrophic storms, one with 10 such events and another with one. You're not predicting which will come to pass, only that one of two will happen, and that they're equally likely.

Given that you don't know which pattern will occur, the standard principles of insurance aren't really of any help in deciding what steps to take, based on the actuarial tables for the two scenarios. In one case, you decide to be very cautious and assume that 10 storms will occur. Then you have to consider how much capital you'll need to reserve given that assumption. If each of the events eventually costs $\$ 1$ billion, then you know you'll need $\$ 10$ billion. Of course, if there's only one catastrophic event, the cost of carrying that collateral has been enormous, since you've been carrying 10 times the amount you needed and the opportunity cost of that capital is not inconsequential.

On the other hand, if you decide there will be only one storm, you'll be under protected. In that situation, the risk you face is financial catastrophe.

What do insurers do in this case? They have several options; all, however, have accompanying downsides. One is to settle on something between the extremes of $\$ 1$ billion and $\$ 10$ billion. If both patterns are equally likely, it could seem perfectly logical to divide the difference and choose $\$ 5.5$ billion as the target. But by doing that you're guaranteed to be wrong 100 percent of the time- 50 percent of the time you'll be overinsured and 50 percent of the time you'll be under-insured, by several billion dollars in both cases. If you're too low, and insuring yourself, you're making yourself liable for risks you can't cover. But if you set the target too high, you're forced to set unattractively high rates. You'll likely end up losing your customers. In many instances, that's happening right now.

If you want to insure property in the Caribbean, for example, you must pay a premium that's roughly 33 percent of the 


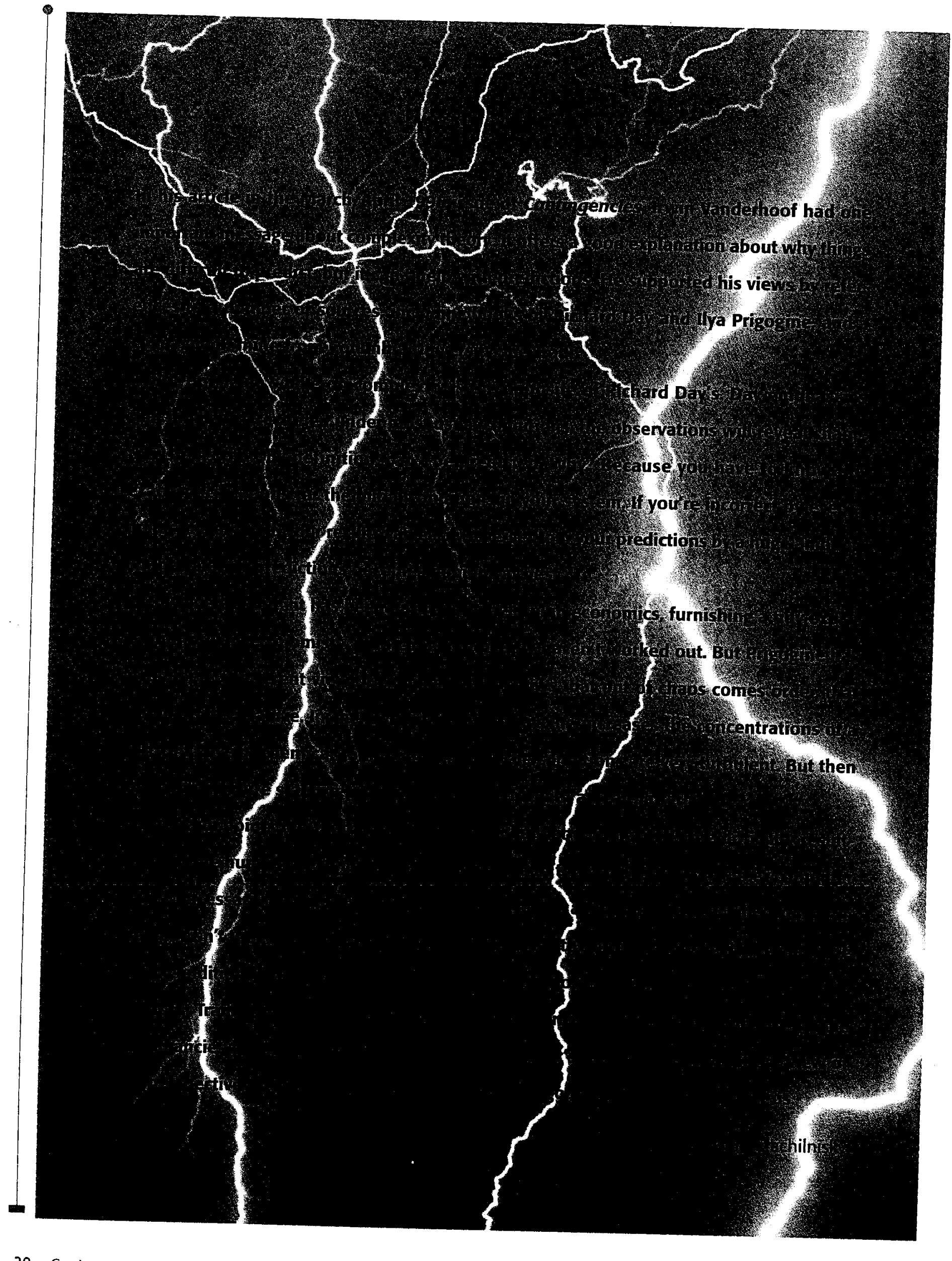


value of the property. You know there isn't really a one-in-three chance of a catastrophic event. But because the possibility may, in fact, be one in 10, or one in two, insurers have to take something like an average. So we end up with 33 percent. As a result, most of the properties in the Caribbean are uninsured.

Another option is self-insurance. Stanford University, for example, purchases no earthquake insurance. For many years, the university covered itself. Some may think of that as a solution, but it isn't. In the end, regulators still look at Stanford and say, "Okay--you're selling insurance to yourself. So all the usual state regulations about insurance apply to the university." Stanford, as a result, has the same burden of accumulating data, record-keeping, and reserves as any insurance company.

\section{Back to the Weather}

Let's think again about those two weather patterns. What do they really mean? They qualify as chaotic attractors-complex systems. As complex as they are, most of them tend to settle into patterns. The problem is that, using the example I gave, the chaotic behavior could settle into two patterns. One is associated with a certain type of weather; the other is associated with another type. Still, there's a lot of uncertainty with these two patterns; you can't make exact predictions-we're talking about averages here. One pattern is associated with just one catastrophic storm, and the other with 10 storms.

With chaotic systems, although you've identified the attractors, you can't predict whether you're going in one direction or another. So in some sense, although chaotic systems are not as chaotic as they appear to be--there's a method in their madness-you don't know in which direction they'll go. The solution is to change our way of looking at them.

\section{The Securities Component}

The securities industry has a different approach to this dilemma than the insurance industry. The insurance industry knows that you can't predict when and where a specific event will hit, so it relies instead on actuarial tables to provide broader (statistically based) predictions inherent in the law of large numbers. This is the principle behind insurance-safety in numbers. You can't predict precisely who will be hit, but you can predict how many people, overall, will be hit.

Even if a given system is chaotic, you still have enough information to allow you to say something about it. What you say takes the form of one, two, or three possible scenarios and, with them, one, two, or three actuarial tables. Selecting from among them is the problem.

The remedy is to use principles from securities markets. These markets don't rely on the sort of statistically based information the insurance industry uses. What they do is hedge. They operate by seeking patterns and, armed with that, hedge against probable downside risks. They hedge, for instance, when they use bonds and equities to provide a cushion against in- terest-rate changes-without looking for the statistical safety in numbers that characterizes insurance procedures. They search for factors that are correlated. Securities houses, then, hedge against correlated events, not by using the law of large numbers or insurance principles, but by using inverse correlation.

The obvious question arises: "What l've got isn't stocks and bonds; it's two equally probable actuarial tables. What am I supposed to use as a hedge?" The answer is-use the same principles that have proved so successful in the securities markets.

You have to hedge the risks in one of your actuarial tables

\section{ALTHOUGH CHAOTIC SYSTEMS ARE NOT AS CHAOTIC}

AS THEY APPEAR TO BE-THERE'S A METHOD IN THEIR

MADNESS-YOU DON'T KNOW IN WHICH DIRECTION

THEY'LL GO. THE SOLUTION IS TO CHANGE OUR WAY

\section{OF LOOKING AT THEM.}

against the risks in the other. You need to look at the risk not as something you're trying to predict statistically, but as the development of different scenarios. Then you have to, in effect, insure yourself by using insurance policies within each of the scenarios. In each case you assume the scenario that's going to occur. Insurance goes as far as possible-- because it's a very efficient method-in dealing with one of the scenarios. But when dealing with multiple scenarios, where you have no way of deciding between them, you have to use a different financial instrument. This instrument is a security contract, one that's contingent not on interest rates but on actuarial tables instead.

In risk management, the key is to think of the future as a combination of two factors. The first is a statistical factor, which is what you're familiar with-the actuarial table. But if you're insecure, as you should be, about what triggers insurable events, your only option is to bet-just like in a casino. If there's one sort of outcome, and you're protected for that, you'll have a shortfall, and if the other scenario happens, and you're protected for that, you'll have too much insurance and the carrying cost will be too high. So what you do is buy securities that pay more in one weather pattern and less in another. Thus, by transferring money between the two possible states, you're protected. In more concrete terms, it's a combination of a modified reinsurance package, which diversifies the risk and protects the insurer against unknown financial risks, and a security, which captures correlated risks that can't be diversified in any way.

So the fact that you can't make predictions becomes irrelevant-as long as you have chaotic attractors, which give rise 
SCOTT \& WHITE TEMPLE, TEXAS

cott \& White, one of the nation's largest medic enters, including a 492 physician clinic with 1 cations, a top rated 139,500 member HMO and a 48 ed teaching hospital affiliated with Texas A\&l niversity Health Science Center College of Medicin cated in Central Texas is actively recruiting for a ctuary. Candidates must have a Bachelors degree ctuarial Science, Math or Statistics and ASA with ears experience in managed care. Responsibilitie clude developing rates and capitation, rating policie hd methodologies, and budget preparation for consultin ctuarial review.

cott \& White provides an outstanding career opportuni pr professional growth along with excellent benefit location assistance and ideal living conditions in th mbelt ( 1 hour North of Austin and $2 \frac{1}{2}$ hours South allas on I-35). Qualified candidates send resume wit lary history to: GRACE COLE, Scott \& White Huma esources, 2401 S. 31st Street, Temple, Texas 76508 ax (254)724-1631; http://sw.org EOE.
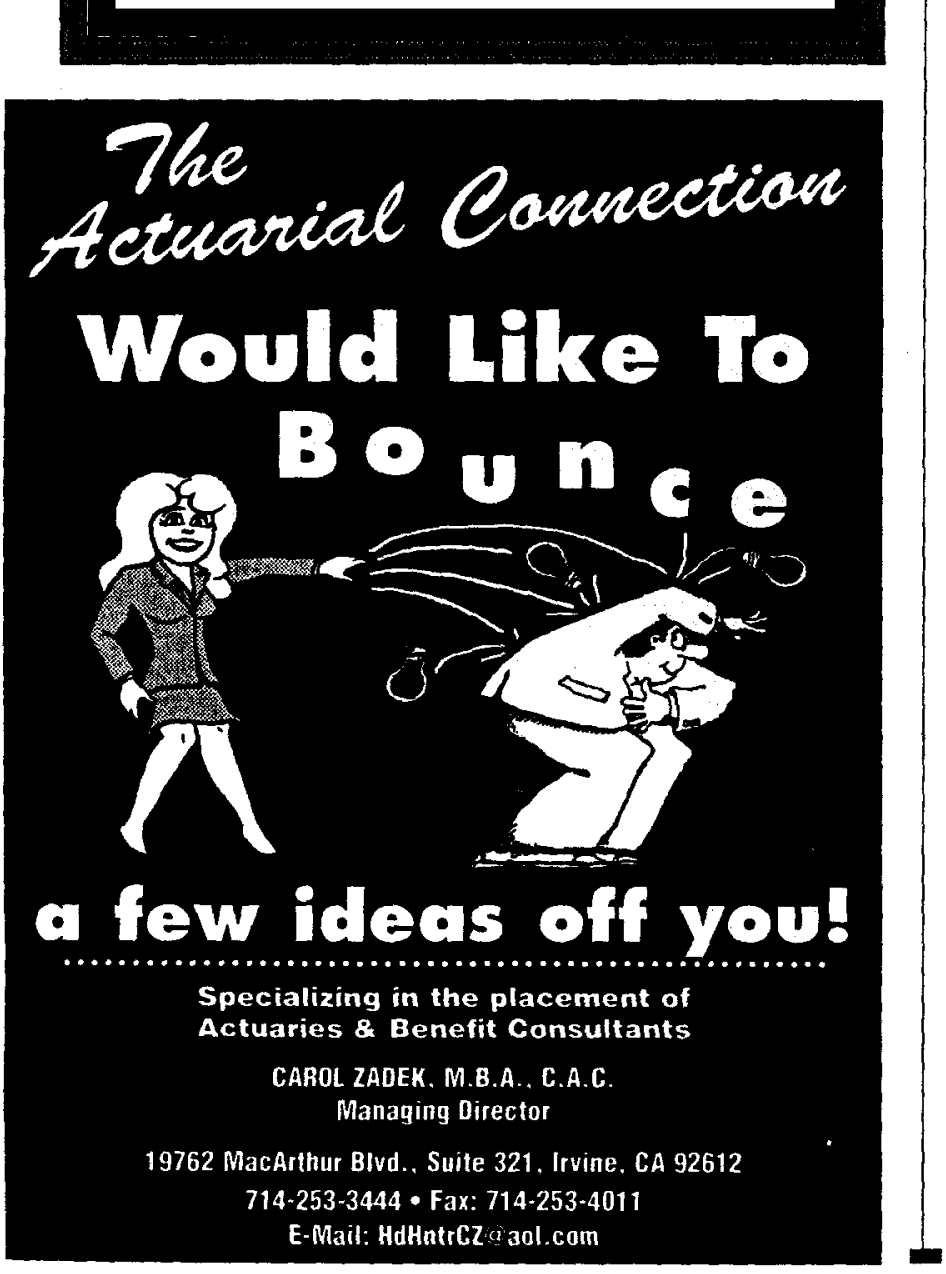

to patterns. While the patterns are not predictable, if you can distinguish a finite number of patterns you're positioned to take effective action and hedge the risk inherent in each pattern by reverse correlation.

So chaotic systems can be used for practical purposes. We live in a world where we need to know what could happen, having used a rational approach to classifying risks. And the risk may well take the form of one of several patterns, with correspondingly different actuarial tables. Once you've understood that risk, take action. Take out a hedge against the risk.

\section{Some Pieces in Place}

While this concept has yet to be implemented totally, some pieces of it, interestingly enough, have been coming onto the market. The Chicago Board of Trade is now selling catastrophe futures, for example. They're a piece of the total puzzle I've described here, since they help you protect against different actuarial tables governing a given segment of time. But the market for these instruments to date has been very thin, because the same people who buy them-insurers-are the people who report how much a given instrument should pay, thus potentially creating a conflict of interest.

Meanwhile, during the summer of 1996, Merrill Lynch and Morgan Stanley floated new instruments, such as environmental bonds, with exactly the same structure. This is a bond with a coupon that, in addition to the standard terms, includes a factor that pays differently depending on the frequency of catastrophic events.

In addition, there have been attempts to adapt the fundamentals of securities to fit the insurance industry-in a word, securitization. There are companies that carry insurance contracts as their main asset (but of course, there are also liabilities); they sell shares in the company, thereby accessing the capital market. Much like Ginnie Mae, you take a large number of risks, pool them, cut the pool into small portions (shares) that are put on the market, and let people invest in the company. This procedure lets companies access capital markets from an insurance base, and that's good, given the potential for losses from a major catastrophe. It's nearly impossible to put aside enough reserves for a "Big One," and the associated cost of doing so is tremendous.

So different pieces of the theory l've advanced here have been implemented, but not the whole thing. The bottom line, then: You can't predict one particular outcome using complexity theory, but you can look for the relevant chaotic attractors. Then, if there turns out to be more than one of these, you can use securities as hedges between them. The actual financial instrument has been created and developed at the Program on Information and Resources at Columbia University, and is in the process of being implemented. It protects against financial as well as natural catastrophes in the most cost-efficient way. 